\title{
Improving Field-Based Experimental Research to Compliment Contemporary Management
}

\section{By Tony Svejcar and Kris Havstad}

I mproving both communication and collaboration between rangeland managers and researchers are among the objectives of this special issue of Rangelands. The impetus for this series of papers was the article by Briske et al., ${ }^{1}$ which questioned the value of rotational grazing relative to continuous grazing for increasing plant and animal production. Although grazing and grazing systems are the focus, we suggest that the general principles contained in our discussion really should apply to a host of landscape-level issues.

If we are to improve communication between managers and researchers (those who develop the science), it would be helpful for each group to understand limitations facing the other, so we are offering a perspective we share as scientists. We can say without reservation that rangeland research is expensive (usually requiring substantial labor inputs), slow, and has to be very targeted. We have the resources to tackle only a small portion of the problems stakeholders bring to our attention. We try to focus on developing general principles because we know we can study only a limited number of plant communities, treatments, and years. In the sections that follow, we try to outline some of the limitations of traditional field research. We strongly believe that science has a major role to play in management decisions, but there are inherent limitations to science that define and constrain its role in informing management.

Spatial scale is one of the more difficult stumbling blocks for integrating science and management. Traditional experimental designs replicate experimental units (things that are measured to evaluate responses to treatments such as plants, plots, pastures, or animals) to account for natural variability so that treatment comparisons can be made. This often requires a relatively small-scale focus. Certainly, there are instances in which principles indentified from research at a small spatial scale have application at larger scales. For example, small-scale plot studies in the early 20th century clearly identified limits to seasonal and early growing season grazing use of individual perennial grasses, such as bluebunch wheatgrass and black grama. We know those identified limits have application to allotment and ranchscale management decisions for maintaining important forage species. Another example would be small-scale work on plant response to fire. The nature of a fire may change with scale, but the principles of plant response are consistent across scales. Those small-spatial-scale principles, in a sense, scale up quite effectively. However, there are also cases in which research is difficult to scale up. For example, we may know how individual plants respond to grazing, but animal preference and grazing distribution come in to play at larger scales to influence plant community response. We may manage to maintain individual species and still shift community structure. We believe this issue of scale deserves much more attention from researchers.

There are reasons to be optimistic that we can overcome the obstacles to better integration of management and research. There have been and continue to be plenty of success stories. Some of the newer tools have helped us all gain a better appreciation and description of scale issues (global positioning systems and geographic information systems for example) and our analysis capabilities will only continue to improve. We believe that some of the tools for research on a larger scale will open the door for further collaborations between managers and researchers. We hope that the discussion that follows will 1) point out some of the limitations of traditional field-based research and 2) provide suggestions for some of the approaches that might help us move forward.

\section{The Scientific Method}

It is constructive to initially discuss some of the approaches used by both researchers and managers. In this and the next section we will outline some of the steps used by each group. These following comments should apply to most natural 
resource-oriented disciplines, but our focus is clearly on rangeland.

Science is generally defined as the acquisition of knowledge that allows us to predict outcomes. Modern science is viewed as a system of acquiring knowledge, usually by applying the scientific method. There are four major steps in a traditional approach.

1) Identify a problem to solve and use experience or published information to make sense of the problem (explain possible outcomes). We will use the Briske et al. ${ }^{1}$ paper as an example of the process. In this case they used prevailing recommendations as the starting point: that is, that there will be benefits to applying rotational grazing above those accrued though the managed use of continuous grazing.

2) Develop specific testable hypotheses pertaining to possible outcomes. A hypothesis is simply an assumed proposition that can be tested in a structured and repeatable fashion (i.e., other people can test your hypothesis). This step requires considerable attention because it drives the rest of the process. The bottom line is that a hypothesis must be written in a manner that allows us to accept or reject the hypothesis once we have completed the process. Continuing with the Briske et al. ${ }^{1}$ example, the hypothesis could be this: rotational grazing will increase plant and animal productivity compared to continuous grazing. We might write that as two separate hypotheses, one for plants and one for animals, because one could prove true and the other false.

3) Design experiments that allow us to accept or reject the hypotheses we developed in step 2. In the Briske et al. ${ }^{1}$ example, they summarized studies that have been performed over the years. So the designs were already determined by the scientists conducting the studies. The following general rules apply as we are designing a new study. Statistical designs and analysis procedures must be determined before the experiments are performed. For decades much of rangeland research was tightly constrained within experimental designs that conformed to classic analyses of variance statistics. It is much more common today to see experimentation employ newer statistical approaches to designs and analyses that are not constrained in this fashion. An excellent example is the set of nontraditional analyses for stream data collected from a large watershed in Wyoming to infer water quality responses to different management practices. ${ }^{2}$ Irrespective of the design and analyses employed, though, statistical procedures are necessary to express some level of confidence that our inferences about treatments are beyond random variation. So replication and random assignment of treatments are big issues., ${ }^{3,4}$ One useful approach for minimizing site differences is the delineation of landscape variation based on ecological sites. ${ }^{5}$ For example, applying experimental treatments, such as different stocking rates, within similar ecological sites helps limit natural variation. This is an approach researchers have generally used, often without a formal system in place. We must ensure to the greatest degree possible that we are not systematically favoring one treatment over another through site selection. ${ }^{6}$

4) Analyze the results of experiments using the preselected statistical procedures and either accept or reject the hypotheses. If we reject a hypothesis, ideally we use the new information in step 1 and repeat the process. In our example, Briske et al. ${ }^{1}$ found that $87 \%$ of prior studies showed no increase in plant productivity with rotational grazing, and $92 \%$ of studies showed no increase in animal production with rotational grazing. So in this case, we suggest the next generation of studies on rotational grazing should focus on issues other than plant or animal productivity. And it happens that society is also asking our profession to focus on a wider range of ecosystem services than plant and animal productivity.

We have provided a brief outline of research based on the scientific method. But to be fair we should point out that not all research is hypothesis-driven, or can be designed in a fashion where a hypothesis can be adequately tested with some acceptable level of confidence. A good deal of the research in the ecological sciences has been more descriptive than experimental and may or may not test a specific hypothesis. For example, the majority of plant community classification research is aimed at describing plant community types rather than testing specific hypotheses. That does not mean a hypothesis could not be developed for some of these studies, but at a minimum, observational studies often open the door for hypothesis-driven research. We should also point out that some beliefs and assumptions do not allow formulation of a testable hypothesis, and so cannot be tested by the scientific method.

Another example of nonhypothesis research used in rangeland management has been the case study approach. This technique has been effectively used on occasion to provide comparisons of different management practices applied at large spatial scales, such as entire ranch levels. We will discuss this approach later in this paper.

\section{Management Defined}

Most of the formal definitions of management revolve around business and managing people, with many of the dictionary definitions reading something like, "the art of managing"-not very helpful. A more useful contemporary definition ${ }^{7}$ would be this: "the guidance and control of action required to execute a program." There are also steps associated with management.

1) Planning. Deciding what needs to happen and when.

2) Organizing. Ensuring that resources are available to carry out the plan. 
3) Staffing or skill acquisition. Analyzing jobs and skill sets required to carry out the plan. If necessary, hiring appropriate individuals or seeking required training.

4) Leading. Determining what needs to be done and getting people to do it (or in the case of a one-person operation doing it yourself).

5) Controlling, monitoring. Checking progress against plans, which may need modifications based on feedback (sounds like adaptive management).

6) Motivating. Stimulating an individual to take action to accomplish a desired goal (could be self-motivation in that one-person operation).

If we use a grazing example, a rangeland manager may have several goals as part of their plan. If private land is involved, then profitability is likely to be a goal along with sustainability and probably meeting some priority conservation objectives. A manager may be responsible for huge acreages and have limited resources to carry out the task. The opportunities for data collection are fairly limited in most cases. Science is useful at several steps in this process including in the design of a management system (planning). Science-based information can help provide a logical starting point. But there are limitations to what we can realistically demand of science. We agree with the following assertion by Provenza: "controlled experiments are not a good tool to investigate various management options, for example, to compare landscape level manipulations such as different grazing systems." ${ }^{8}$ However, these points may not be relevant if a manager is responsible for small or relatively uniform land areas, or the outcomes of interest are not at a landscape scale.

\section{Scale}

Spatial scale presents one of the more challenging impediments to bridging rangeland science and management in the 21 st century. Today we are much more aware that rangeland dynamics are influenced by drivers at multiple scales from plants, patches, pastures, properties, landscapes, watersheds, continents, and, eventually, from the global scale. We define "drivers" as underlying climatic, economic, social, political, or biotic forces that cause change, such as drought, species invasion, management activities, or human population growth. In traditional experimental design, the goal is to account for background variability so we can compare treatments. The level of landscape variability for most rangelands is very high, ${ }^{9}$ which forces researchers to use relatively small experimental units. However, an average family ranch in the Great Basin, as an example, may graze cattle on 30,000 acres or more of rangeland. Let's assume a 400-cow operation and rangeland rated at 10 acres per animal unit month (AUM). If there was a 7-month grazing period (April through October), the land requirement would be 400 cows $\times 10$ acres/AUM $\times 7$ months $=28,000$ acres. Over that size of land area there may be large elevation gradients, a variety of different plant communities, and a variety of responses to grazing. It would be virtually impossible to use a traditional experimental approach to compare grazing systems at the entire ranch level. That would require finding a similar adjacent ranch on which to apply the other system and even that would not address the need for replication. In the western United States, it is very difficult to find similar ranches; each has its own individual set of resources. These issues are not unique to grazing, but also apply to many other issues including water quality of streams and rivers, habitat for highly mobile wildlife species, landscape expansion of invasive species, and wildfire impacts.

A more reasonable application of science to management might involve decision-making about individual pastures, plant communities, or species of interest. For example, we know from experimental evidence that early-season grazing favors young bitterbrush plants and late-season grazing can have negative impacts. If favoring bitterbrush is an issue for a particular pasture, then management informed by science would result in grazing before bunchgrasses reach the boot stage. ${ }^{10}$ There is published evidence that cattle will use riparian areas harder after the uplands dry and ambient temperatures increase. ${ }^{11}$ If riparian condition is an issue, pastures containing streams may need to be used early, or for a relatively short period if used late in the season. In the past many rotational grazing systems were set up to vary timing of defoliation from year to year. There are numerous studies showing that defoliation at specific growth stages (typically the boot stage in grasses) can have a negative impact on subsequent forage production. ${ }^{12}$ Of course, these are decisions that managers must make based on a host of factors, including experimental science.

\section{Recommendations}

Given these concerns, issues, and limitations facing science and its application to management, we provide the following five recommendations to improve the capacity of science to further inform management.

1) Incorporate relevant spatial scales. It appears to us that the issue of scale really needs more attention from our profession and indeed from all natural resourceoriented professions. We need a common framework and language, which allows for improved communication and planning. There is currently a good deal of frustration among managers and policy-makers who are increasingly being asked to address issues at larger scales often with inadequate science. In many cases, we within the rangeland management profession have not discussed which problems to address at which scale. For example, reseeding rangeland may be a small-scale decision, but the specific location of a seeding on the landscape may have wildlife benefits. In this hypothetical case, seeding may have implications for reducing bare ground or invasive species at the patch level on many sites, or it could also have implications for wildlife if 
conducted at a landscape position deemed to be important deer winter range. We suggest that the article by Bestelmeyer et al. ${ }^{5}$ provides a good starting point in spatial scale discussions.

2) Encourage multisite studies. Rangelands can be extremely variable and responses to individual treatments will likely vary with site. Without multisite studies, we are often forced to make generalizations that extend beyond the range of the data. An example of a multisite study would be that by Miller et al. ${ }^{13}$ Plant community response to western juniper invasion was quantified on 108 sites and responses were grouped into broad categories. This approach allowed managers to predict responses to juniper control based on site characteristics. This study is also a good example of cooperation between managers and researchers; managers provided the land and applied the treatments, and researchers collected and analyzed the data and published the results. However, we recognize that there will always be significant geographical gaps in our areas of study and site-specific applications. The important role of science-based models that can reflect larger principles and broader inferences cannot be underestimated.

3) Encourage enterprise-level research where possible. We presented the challenges to this type of work previously (comparing entire ranches, or other large-scale entities). But where opportunities exist, we should encourage this type of large-scale approach. And it may be necessary to select portions of the larger enterprise to compare. An excellent example of the case study approach was the report of Hinton ${ }^{14}$ that compared 15 different ranch properties in Queensland, Australia, to draw inferences about different management practices and their profitability. The case study approach could be used more often and more widely in rangeland management with considerable effect. However, the limitations of this approach should be recognized. Often, the case study approach lacks a true control treatment, or an ability to specifically identify the causes, or underlying mechanisms, of an observed response. Case studies also require willing participants for relatively long periods of time. Though the inferences drawn from case studies may not be subjected to statistical rigor, and are often regarded as weak, this approach provides real opportunities to observe in a structured fashion large enterprisescale application of management practices. Case studies of this nature could be designed to involve interested parties, from landowners to management professionals as well as the scientific community and interested public. It would be extremely important that this type of approach be developed for long time periods to contend with temporal variability in climate (as discussed in the next section). Measurements may not be necessary every year, but rather could be spread over a reasonable time horizon.
4) Commit to long-term studies. Rangelands are well known for tremendous year-to-year variation. Rangeland drivers, such as climate, may not be sufficiently well acknowledged by either scientists or managers when using research results to inform management decisions. Increasingly, we are recognizing the role of specific episodes, such as major droughts that occur in quasidecadal time scales, in driving rangeland systems in response to management. ${ }^{15}$ Research to evaluate novel management practices would have to be of sufficient duration to explain how the systems in question fare during the type of episode that often shapes a landscape. In addition, changes in grazing systems may have subtle effects that take years to be expressed.

5) Add controls (nontreated areas) to help evaluate management effects. Given the variability inherent in rangelands (over both time and space), tremendous value can be added to monitoring efforts by including controls in the design of management projects. In many cases, the control areas can be relatively small and still allow an objective assessment of treatment effects. The side-byside comparisons of controls and treatment areas can be useful in explaining treatment results to stakeholders and the interested public. In many cases, this is an area where managers may want to engage researchers to help with initial designs and sampling protocols. We cannot overemphasize the strength of a treatment/control comparison compared to simply conducting long-term monitoring. This approach maximizes our ability to learn while applying management. ${ }^{16}$

\section{Concluding Remarks}

Rangeland management has long been described as both a science and an art. ${ }^{17}$ Certainly, the management of rangeland resources, especially during the last half of the 20th century, can be characterized by practices commonly informed by science. There are a number of management practices in which synthesized bodies of experimentally derived observations have provided science-based rationales for their application and use. The collection of recorded observations from different field experiments in diverse environments has often resulted in reasoned understandings of relevant ecological processes and the structures and/or dynamics of these systems. At its core, rangeland management is a set of practices implemented over time that reflect a manager's understanding of those structures and dynamics. A well-articulated body of scientific evidence can enhance understanding beyond generational knowledge or sitespecific experiences. Tension, though, between practitioners of science and art can result if synthesized knowledge is seen as either counter to or unsupportive of anecdotal knowledge or site-based perceptions. We have acknowledged this tension in the past, and understand that what we learn from science is provisional and we will continue to learn. ${ }^{18}$ At issue here is the reconciliation of existing scientific evidence 
with a perceived understanding accumulated from either personal or generational experiences, or accumulated over time at specific sites.

For more than 400 years Western culture has been closely linked to science and scientific advances from medicine to physics to genetics to engineering to ecology. However, throughout this history we have seen science progress and provide its greatest contributions when it is understood within the general culture and eventually applied by the general population. Rangeland management may be more correctly viewed, then, as the artistic application of sciencebased principles. The role of science in rangeland management is not to try to evaluate each novel approach of the artist, but to continue to provide the principles that have application to the art. Science has provided basic principles for management tied to the spatial and temporal scales and uses of the 20th-century land manager. The challenge for science today is to provide the principles for the spatial and temporal scales and the uses confronting the 21st-century resource manager. What has changed is the demand for a wider variety of goods and services, and increasing recognition of the linkage among spatial scales. We think that these science-based principles will emerge from a combination of cross-scale, enterprise-level, interdisciplinary, and long-term studies. We have an excellent base of research and management experience, which can lead us to the next generation of grazing hypotheses and management treatments. We suggest that cooperation and interaction between managers and researchers will be critical for future success in this arena.

\section{Acknowledgments}

We thank Chad Boyd and Roger Sheley for thoughtful comments on an earlier draft, the constructive comments of two anonymous peer reviewers, and guidance provided by the editor of this special issue, Joel Brown.

\section{References}

1. Briske, D. D., J. D. Derner, J. R. Brown, S. D. Fuhlendorf, W. R. Teague, K. M. Havstad, R. L. Gillen, A. J. Ash, And W. D. Willms. 2008. Rotational grazing on rangelands: reconciliation of perception and experimental evidence. Rangeland Ecology and Management 61:3-17.

2. Ellison, C. A., Q. D. Skinner, and L. S. Hicks. 2009. Assessment of best-management practice effects on rangeland stream water quality using multivariate statistical techniques. Rangeland Ecology and Management 62:371-386.

3. Larsen, R. E., W. C. Krueger, M. R. George, M. R. Barrington, J. C. Buckhouse, and D. E. Johnson. 1996. Livestock influences on riparian zones and fish habitat: literature classification. Journal of Range Management 51:661664.

4. SARR, D. A. 2002. Riparian livestock exclosure research in the western United States: a critique and some recommendations. Environmental Management 30:516-526.
5. Bestelmeyer, B. T., A. J. Tugel, G. L. Peacock, Jr., D. G. Robinett, P. L. Shaver, J. R. Brown, J. E. Herrick, H. Sanchez, and K. M. Havstad. 2009. State-and-transition models for heterogeneous landscapes: a strategy for development and application. Rangeland Ecology and Management 62: $1-15$.

6. Peterson, R. G. 1985. Design and analysis of experiments. New York, NY, USA: Marcel Dekker, Inc. 429 p.

7. Shead, M. 2007. Definition of management. Available at: www.leadership501.com/definition-of-management/21/. Accessed 29 July 2009.

8. Provenza, F. D. 2000. Science, myth, and the management of natural resources. Rangelands 22:33-36.

9. Brown, J. R., T. Svejcar, M. Brunson, J. Dobrowolski, E. Fredrickson, U. Krueter, K. Launchbaugh, J. SouthWORTH, AND T. Thurow. 2002. Are range sites the appropriate spatial unit for measuring and monitoring rangelands? Rangelands 24:7-12.

10. Ganskopp, D., T. Svejcar, F. Taylor, and F. Farsvedt. 2004. Can spring cattle grazing among young bitterbrush stimulate shrub growth? Journal of Range Management 57:161168.

11. Parsons, C. T., P. A. Momont, T. DelCurto, M. McInnis, and M. L. Porath. 2003. Cattle distribution patterns and vegetation use in mountain riparian areas. Journal of Range Management 56:334-341.

12. Ganskopp, D. 1988. Defoliation of Thurber needlegrass: herbage and root responses. Journal of Range Management 41:472-476.

13. Miller, R. F., T. J. Svejcar, and J. A. Rose. 2000. Impacts of western juniper on plant community composition and structure. Journal of Range Management 53:574-585.

14. Hinton, A. W. 1995. Land condition and profit: a study of Dalrymple Shire properties. Queensland, Australia: Department of Primary Industries, Project No. 90R535, National Landcare Program No. 91. 41 p.

15. Stafford Smith, D. M., G. M. McKeon, I. W. Watson, B. K. Henry, G. S. Stone, W. B. Hall, and S. M. Howden. 2007. Learning from episodes of degradation and recovery in variable Australian rangelands. Proceedings of the National Academy of Sciences of the United States of America 104:2069020695.

16. Reever-Morghan, K. J., R. L. Sheley, and T. J. Svejcar. 2006. Successful adaptive management-the integration of research and management. Rangeland Ecology and Management 59:216-219.

17. Stoddart, L. A., A. D. Smith, and T. W. Box. 1975. Range management. 3rd ed. New York, NY, USA: McGraw-Hill. $532 \mathrm{p}$.

18. Watson, L. W., D. G. Burnside, and A. M. Holm. 1996. Event-driven or continuous; which is the better model for managers? Rangeland Journal 18:351-369.

Authors are Research Leader, USDA-Agricultural Research Service (USDA-ARS), Eastern Oregon Agricultural Research Center, 67826-A Hwy 205, Burns, OR 97720, USA, Tony. Svejcar@ars.usda.gov (Svejcar); and Research Leader, Jornada Experimental Range, New Mexico State University, Las Cruces, NM 88003, USA (Havstad). 